\title{
A Metaphor Analysis of Love Allusions in A Dream of Red Mansions
}

\author{
Lin Qiuming ${ }^{1} \&$ Li Danyang ${ }^{2}$ \\ ${ }^{1}$ Faculty of English Language and Culture, Guangdong University of Foreign Studies, Guangzhou, P.R. China \\ ${ }^{2}$ Institute of Education, University College London, London, UK \\ Correspondence: Lin Qiuming, Guangdong University of Foreign Studies, Guangzhou, P.R. China. Tel: 86-137- \\ 9811-7687. E-mail: linqiuming@gdufs.edu.cn
}

Received: September 23, 2020; Accepted: October 9, 2020; Published: October 10, 2020

\begin{abstract}
The paper explores two love allusions, 'the pledge between plant and stone' and 'Jin's marriage' in the Chinese literary classics A Dream of Red Mansions written by Cao Xueqin and provides new explanations to the theme of the novel. Nearly 20 metaphorical expressions in the novel are selected through Critical Metaphor Analysis with 6 specifically representational examples analyzed in the paper by building integration networks based on Conceptual Integration Theory (CIT). The findings are as follow: 1) the counterculture of 'plant and stone' is embodied in the mythological stories at the beginning of the novel. 2) a 'nested integrational network', originally proposed by the researchers, links the mythological narrative space and the fictional human world space. 3) the comparison between integration networks of the two love allusions shows anti-feudalism of the author Cao Xueqin. This paper offers an interpretation of the novel from the aspect of cognitive linguistics, which, in turn, could promote the development of CIT within this field.
\end{abstract}

Keywords: A Dream of Red Mansions, metaphor, Conceptual Integration Theory (CIT), the pledge between plant and stone, Jin's marriage

\section{Introduction}

As one of the traditional Chinese novels, A Dream of Red Mansions has been studied from various perspectives by scholars both at home and abroad. The previous studies mostly fall into four branches: translational studies, cultural and transcultural studies, literary studies and semantics and pragmatics studies. This paper however, aims at interpreting the love allusions in the novel from cognitive perspective which is rarely touched in the studies of A Dream of Red Mansions.

Metaphor has long been considered as a powerful weapon to explore and depict this world. Metaphor study dates back more than 2500 years ago. Ever since the publication of Metaphors we live by written by Lakoff and Johnsen (2003), people began to view metaphor as a cognitive method rather than a rhetorical device. Another breakthrough should be Conceptual Integration Theory (CIT) proposed by Fauconier (1997) which views the whole cognitive process as being dynamic, integrating concepts from different frames.

The researchers adopt the Conceptual Integration Theory to assess the two love allusions, 'the pledge between plant and stone' and 'Jin's marriage' in the novel. The integration networks could show the cognitive process of readers.

\section{Literature Review}

\subsection{Countercultural Essence of 'The Pledge Between Plant and Stone'}

In the previous studies, researchers mainly explained 'the pledge between plant and stone' from three aspects: cultural anthropology, connotational exploration and cultural development and origin (Xu, 2018).

Cultural anthropology aims at revealing the common traits of human beings through the observation of a large number of tribes and groups of people. Previous studies have interpreted 'the pledge between plant and stone' mainly as 'gender worship'. Huang Haochong (2001) argues for 'gender worship' as a kind of collective unconsciousness which dates back to ancient times. The stone implies the worship of penis while the begonia represents the worship of vulva. He lists a series of works which compare the penis to pillars or arrows made of stone to support his interpretation of 'the stone' as 'the worship towards penis' (more precisely, towards the masculinities power and strength). Whereas, his claim that the plant in the love allusion represents the worship towards vulva is obscure. Based on the linguistic data of that time, flowers, especially begonia, would be used to 
refer to women or their good personalities. However, he explains the 'plant' as begonia only on the account that begonia is rouge which represents the plot that Jia Baoyu has the habit of eating the rouge on girls' mouths. His idea is unique but still needs further proof. Other authors (e.g. Zheng (2000) and Li (2006)) who also advocate gender worship all fail to give sufficient evidence to interpret 'the plant' as the worship towards women.

To conclude, three obvious problems of this perspective are as follow: 1) little evidence to support the explanation of 'the plant' as 'begonia', further as 'women worship'; 2) the ignorance of 'the pledge', the last but not least significant target in the metaphor; 3) huge time span and cultural difference between the time when Cao lived and when 'gender worship' was influential. Therefore, 'gender worship' may be inappropriate to assess the implied meaning of 'the pledge between plant and stone'.

The second aspect, connotational exploration surveys the love allusion by exploring the underlying meanings of words and expressions. However, this is even more doubtful. Zhou Ruchang demonstrates in his book that the pledge between plant and stone does not refer to Jia Baoyu and Lin Daiyu but to Jia Baoyu and Shi Xiangyun merely for Shi Xiangyun's family name (李, 'Li' with the meaning of plant). There is no need to nit-pick on every word to understand the love allusion since it may end up far from the original intention of Cao Xueqin.

The last school of thought is the origin and development of the Chinese culture, which is what the researchers recommend. According to Chen Hong (2016), intertextuality should be applied to analyze the love allusions. The image of plant and stone could be found in abundant Chinese poems:

Where Chinese characters have been provided, the researchers' personal interpretations will be summarized underneath.

心非木石岂无感, 吞声蹶躅不敢言。（《鲍明远集》卷 8 《拟行路难 · 其三》)

(In Bao Zhao's poem, the plant and stone represent something without emotion. The poet cries out that he is not wood or stone since his sadness of not being appreciated by the emperor is overwhelming.)

人非木石皆有情。（《元氏长庆集》卷 4 《李夫人》)

(In the above poem, to express the lament and grief smoldered in his heart, the poet likens himself as anything but the plant and stone which, according to the poet, lack the feelings and spirits of the human beings.)

So, as the prevailing symbolic images in the Chinese poems suggest, the plant and stone should be interpreted as something indifferent which is country to the characteristics of Jia Baoyu and Lin Daiyu (Jia Baoyu claimed himself full of sickness and of woe while Lin Daiyu is the representative of sensitive women). Xu Zhongrong (2018) provides one possible explanation for this contradiction. He states that using the indifferent stone and plant to stand for the moving love pledge between Jia Baoyu and Lin Daiyu actually highlights the preciousness of the feeling. This, according to his belief, is a kind of writing technique (Chen, 2016). Thus, the plant and stone serve as a foil to set off the precious emotion between Baoyu and Daiyu.

Previous studies made the point of the contradiction or incoherence between the love tokens and the characters in the novel. The researchers argue that anti-entrenched forces which highlight the countercultural essence of the plant and stone do exist in this metaphor. This however, is in accordance with the anti-feudalism belief of Cao Xueqin. A mythological integration network has been built and analyzed in section 4.1.1. to support this claim.

\subsection{Traditional Culture in 'Jin's Marriage'}

The love allusion of Jin's marriage contains orthodox thoughts from ancient China.

Yang Jiayou and Yang Jianhong (2010) argue that Jin's marriage represents traditional Chinese culture that man had to pursuit high official positions and wealth to get a promising future. And a perfect marriage should be based on equal social status. The match between gold and jade therefore should be interpreted as the perfect marriage.

Abundant Chinese poems view gold and jade as valuable and holly things or men with high social status:

Where Chinese characters have been provided, the researchers' personal interpretations will be summarized underneath.

\section{金舆巡白水，玉堑驻新丰。（《过旧宅二首》李世民）}

(Li Shimin is the emperor of Tang Dynasty. This sentence described the scene when he passed his old house in Xin Feng. The Chinese character '金', gold in English, presented the gorgeousness of his carriage. Likewise, the Chinese character '玉', jade in English, indicated that the carriage was decorated by jade. Gold and jade were used as something valuable and precious.) 
孟子之谓集大成。集大成也者, 金声而玉振之也。金声也者, 始条理也; 玉振之也者, 终条理也。（《孟 子·万章下》)

(Mencius claimed that a saint processed virtuous quality from birth to death. Here the gold and jade are used to represent the virtues of the saint.)

It has conclusively been shown that the metaphor Jin's marriage should be interpreted as the combination of two people with high and equal social status.

\subsection{Summary}

Data from several studies suggest the countercultural essence of 'the pledge between plant and stone', namely interpreting 'the plant and stone' as objects being emotional contrary to the traditional images in Chinese poems. What they fail to achieve is to provide a proper explanation to the author's purpose for using the metaphor in an anti-entrenched way. This however, could be figured out with CIT which reveals the internal cognitive process of the readers. It will be analyzed in section 4.1.

The traditional culture embedded in Jin's marriage is generally acknowledged, which is actually only demonstrated by intertextuality with discourses presenting the traditional culture in the previous studies. By adopting CIT, the seemingly separated process of entextualisation (Blommaert, 2005) could be integrated into one integration network.

The researchers aim to illustrate the cognitive process of the readers when interpreting the two love allusions.

\section{The Study}

\subsection{Research Questions}

The paper mainly answers the following two questions: 1) How is the counterculture of 'the pledge between plant and stone' expressed through integration networks in the novel? 2) What is the theme expressed through the comparison between the integration networks of the two love allusions?

\subsection{Theoretical Framework}

\subsubsection{Conceptual Integration Theory}

Conceptual Integration Theory is based on Mental Space Theory (Fauconnier, 1994). Mental spaces are the conceptual packets in our minds formed when we are doing communication or comprehension. They are the containers of the perceptions, images or memories in our minds (Fauconnier, 2002). It is the gathering of thoughts just like the set of numbers in mathematics. And there are three types, four in total, mental spaces in one integration network.

\section{(a) Input Spaces}

There are two input spaces in CIT. They play similar roles like the source and the target domains in Conceptual Metaphor Theory (CMT). Whereas, according to CMT, it is only a one-way mapping mechanism from the source domain to the target domain. Researchers adopting CIT argue for the interactional effects between the two input spaces.

Take the famous metaphor This surgeon is a butcher as an example. In this metaphor, elements in the input space 1 are all about 'surgeon', like the scalpel, the operating table, the patient and the entire process of operation, while in input space 2 about 'butcher', including the knife, the livestock, the killing bed and the entire process of animal slaughter. Therefore, these two input spaces have the relations of one-one correspondence and also have mutual effects on each other.

\section{(b) Generic Space}

Generic space is the common schema of the two input spaces. Generally speaking, it is consisted of abstract concepts, relations or roles, which determine the core projection from input spaces to blended spaces.

In the metaphor This surgeon is a butcher, it can be concluded that the schema of both the two systems includes the agent, the patient, the instrument, the location and the behavior involving blood.

\section{(c) Blended Space}

Blended space is the most significant and creative part of CIT. Elements in the input spaces are projected into blended space. Then they go through processes including composition, completion and elaboration under the schema of generic space. The entrenched metaphors which are formed by traditional culture and previous experiences in our mind generate new cognitive information (emergent structure) in blended space to enrich the concepts in the cognitive processes (Sun, 2019). 
Conceptual integration networks are formed by the above mental spaces associated with each other. And they corelate through the following three means:

(a) Mapping

Mapping is the most basic way to link the elements of one set with their counterparts in another set. Likewise, in the conceptual integration network, constituents of each input space map with their counterparts in another one. According to Fauconnier, mapping between domains is the fundamental way to carry out cognitive activities and to generate new meanings.

In the metaphor This surgeon is a butcher, 'surgeon' in the input space 1 will be mapped with 'butcher' in the input space 2.

(b) Projecting

Projecting is the method to transfer elements in the input spaces into the blended space so that the following integration network can be formed.

In the metaphor This surgeon is a butcher, 'surgeon', 'patient', 'operation' etc. in input space 1 and 'butcher', 'livestock', 'animal slaughter' etc. in input space 2 are projected into the blended space.

(c) Compressing

Compressing is the process and final result of the action in the blended spaces. By composition, completion or elaboration, new blended structures will be formed which would be compressed structures.

In the metaphor This surgeon is a butcher, 'butcher-like surgeon', 'patient treated as livestock' etc. are the compressed phrases in blended space.

\subsubsection{Four types of Conceptual Integration Networks}

\section{(a) Simplex Network}

This is the simplest network of all. In this kind of network, there will be only one frame in the two input spaces with another one being a null set containing only abstract elements. It is often used when we talked about kin's relations. For example, in the sentence Alice is my mother, the input space 1 contains only the name of 'Alice' which is a null set and not embedded in any frame. In input space 2, there is the element my mother which is included in a family frame. Therefore, integration network is constructed through mapping the null set Alice with the family frame my mother. However, in the real-life scenes, these kinds of integration networks are quite rare since they usually coexist with more complex cognitive networks.

(b) Mirror Network

In this kind of network, the two input spaces share the same frame. However, different input spaces represent different facets of the frame and the elements integrate in the blended space to generate new structures.

For example, imagine a man going to a commute trip to a mountain. The process of going up and down could be the input space 1 and 2 respectively which are under the same frame (Barbara, 2017).

\section{(c) Single-Blended Networks}

If an integration network is single-blended, it means that both the input spaces have an independent frame structure. Whereas, when they are integrated in the blended space, only one frame will play the dominant role.

In the above example, The surgeon is a butcher, the input space 1 contains the medical frame while the input space 2 involves the frame of butcher. However, when all the elements are projected into the blended space, it is the feature of butcher frame that signifies the meaning of the emergent structures.

(d) Double-Blended Networks

Likewise, if the integration network is double-blended, it also has independent frames for each input space. However, both the frames are included in the emergent structures. And it is often the case that the elaboration of single-blended networks is the generation of double-blended networks.

For example, if we expand the analogy The surgeon is a butcher to all the incompetent and ruthless clerks are butchers, then there will be two sets of frames in the blended spaces.

\subsection{Research Method}

The researchers collect and select representational metaphors based on Critical Metaphor Analysis (CMA) proposed by Charteris-Black (2004). More specifically, three separate steps are included: identification, comprehension and interpretation (Lan, 2013). Identification is the study of the original text to select metaphorical 
expressions. In this study however, only expressions relating to the two love allusions would be taken into consideration. Comprehension is a kind of pragmatics to further understand the underlying meanings; And interpretation is the analysis, categorization and reorganization of the selected texts to understand the embedded social and cultural connotation (Charteris-Black, 2004).

To be more specific, the analysis will only be around the following units: 1) the plant and stone, 2) Attendant Shen Ying and Vermilion Pearl Plant, 3) Jia Baoyu and Lin Daiyu, 4) the gold and jade 5) Jia Baoyu and Xue Baochai.

6 out of 20 metaphorical expressions have been selected and presented to lay the foundations for the integration networks in this paper. Figure 1 illustrates the major three integration networks discussed in the article. Additionally, there is also a 'nested integration network' proposed to better reveal the hidden relationships.

Network 1 (N1) includes Jia Baoyu and Lin Daiyu (input space 1) and the plant and the stone (input space 2). Network 2 (N2) includes Jia Baoyu and Xue Baochai (input space 1) and the gold and jade (input space 2) while network 3 (N3) the plant and the stone (input space 1) and Attendant Shen Ying and Vermilion Pearl Plant (input space 2).

In order to answer the first question, the countercultural essence of 'the pledge between plant and stone', analysis will be focused on the N1 and N3. In terms of question two, the theme of the novel, comparison will be made between $\mathrm{N} 1$ and $\mathrm{N} 2$.

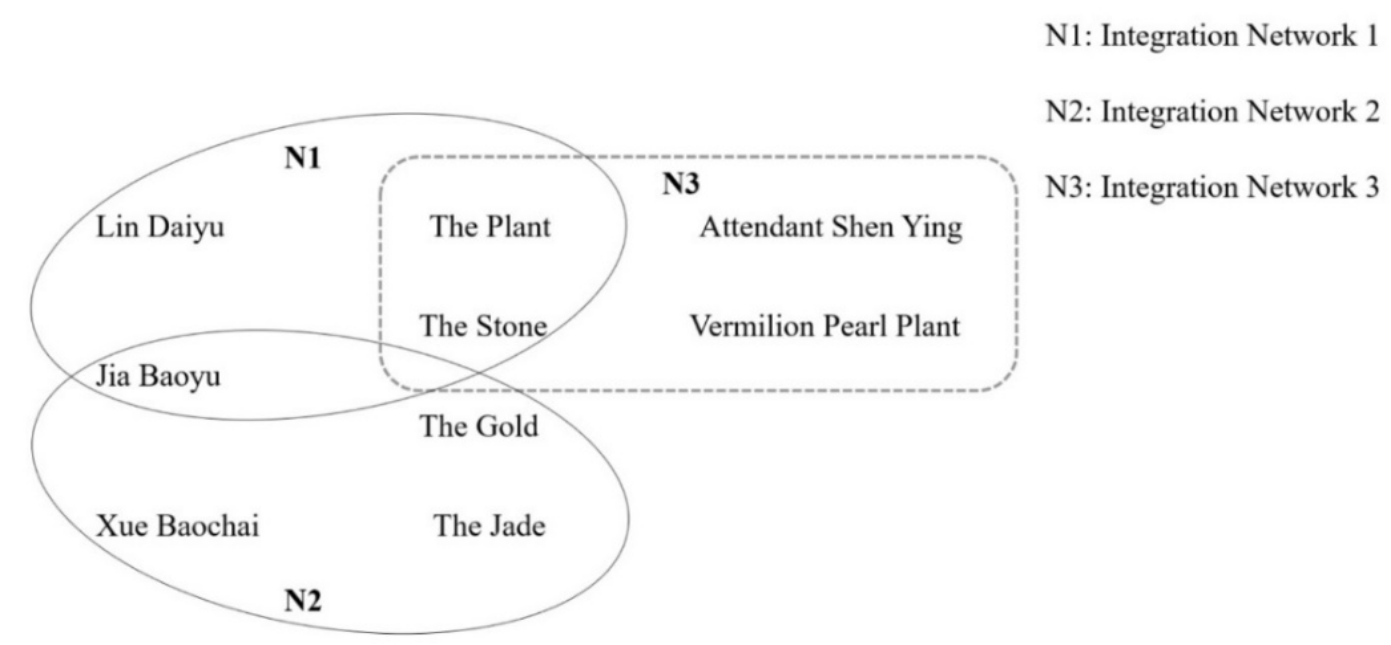

Figure 1. Three integration networks in the study

\section{Data Analysis and Discussion}

\subsection{New Explanation to the Counterculture of 'The Pledge Between Plant and Stone'}

4.1.1 Mythological integration network of 'the pledge between plant and stone'

One of the most significant features of A Dream of Red Mansions is the mythological narrative space in chapter 1. In chapter 1, Zhen Shiyin, the main character, has a dream among which a monk and a Taoist priest holding a stone come towards him. They talk about the origin of the stone which is the provenance of the pledge between plant and stone:

Attendant Shen Ying obligates Vermilion Pearl Plant who becomes Vermilion Pearl and determines to repay his grace. Therefore, when Attendant Shen Ying plans to visit the world of men in the form of human being, Vermilion Pearl decides to follow him and repay his kindness with as many tears as she can shed all through her life.

This myth created in chapter 1 foreshadows the following plot, which is the basis for the cognitive process in later chapters.

Another crucial feature of A Dream of Red Mansions is that it presents the ending of the novel at the very beginning, specifically in chapter 5. Chapter 5 describes the dream Jia Baoyu has where he visits Illusory Land of Great Void. He listens to a series of songs named 'Dream of Red Mansions'. And the second song goes like this: 
Where Chinese characters have been provided, the official translation from Yang Xianyi will be presented underneath.

[终身误] 都道是金玉良缘，俺只念木石前盟。空对着山中高士晶莹雪，终不忘世外仙妹寂寞林。叹人间 关中不足今方信。纵然是齐眉举案, 到底意难平。( 《红楼梦》第五回)

\section{A LIFE MISSPENT}

Well-matched, all say, the gold and the jade;

I alone recall the pledge between plant and stone.

Vainly facing the hermit in sparkling snow-clad hills

I forget not the fairy in lone woods beyond the world.

I sigh, learning that no man's happiness is complete:

Even a pair thought well-matched

May find disappointment. (Yang: 80)

This is the first time that the author, Cao Xueqin proposes the pledge between plant and stone. Cao creates this pledge which not only corresponds to the mythological story in chapter 1 but also foretells the intimate relation of Jia Baoyu and Lin Daiyu.

Therefore, the integration network 3 (N3) can be built:

Figure 2 is the detail of integration network 3 (N3). This is a simplex integration network. Attendant Shen Ying and Vermilion Pearl fall into the mythological frame while the plant and stone belong to the frame of natural object. According to the plot, the predecessor of Vermilion Pearl evolves from Vermilion Pearl Plant which corresponds to the plant in input space 2. Likewise, the plot that Attendant Shen Ying travels the mundane world with a stone directly links the element (Attendant Shen Ying) in input space 1 with his counterpart (the stone) in input space 2. The main frame in generic space is the relation between elements. Therefore, the 'repaying' relation between Attendant Shen Ying and Vermilion Pearl is projected into the blended space while in input space 2, the target elements, the plant and stone are projected into it with obscure relations. In the blended space, the mythological frame takes the leading role which endows the repaying relation to the target elements. Consequently, the emergent structure, 'the pledge between plant and stone' pops up in readers' minds.

We could see that at the very beginning of this novel, the author gives the plant and stone a countercultural interpretation, mutual support and aid, which also lays the foundation for the later integration networks.

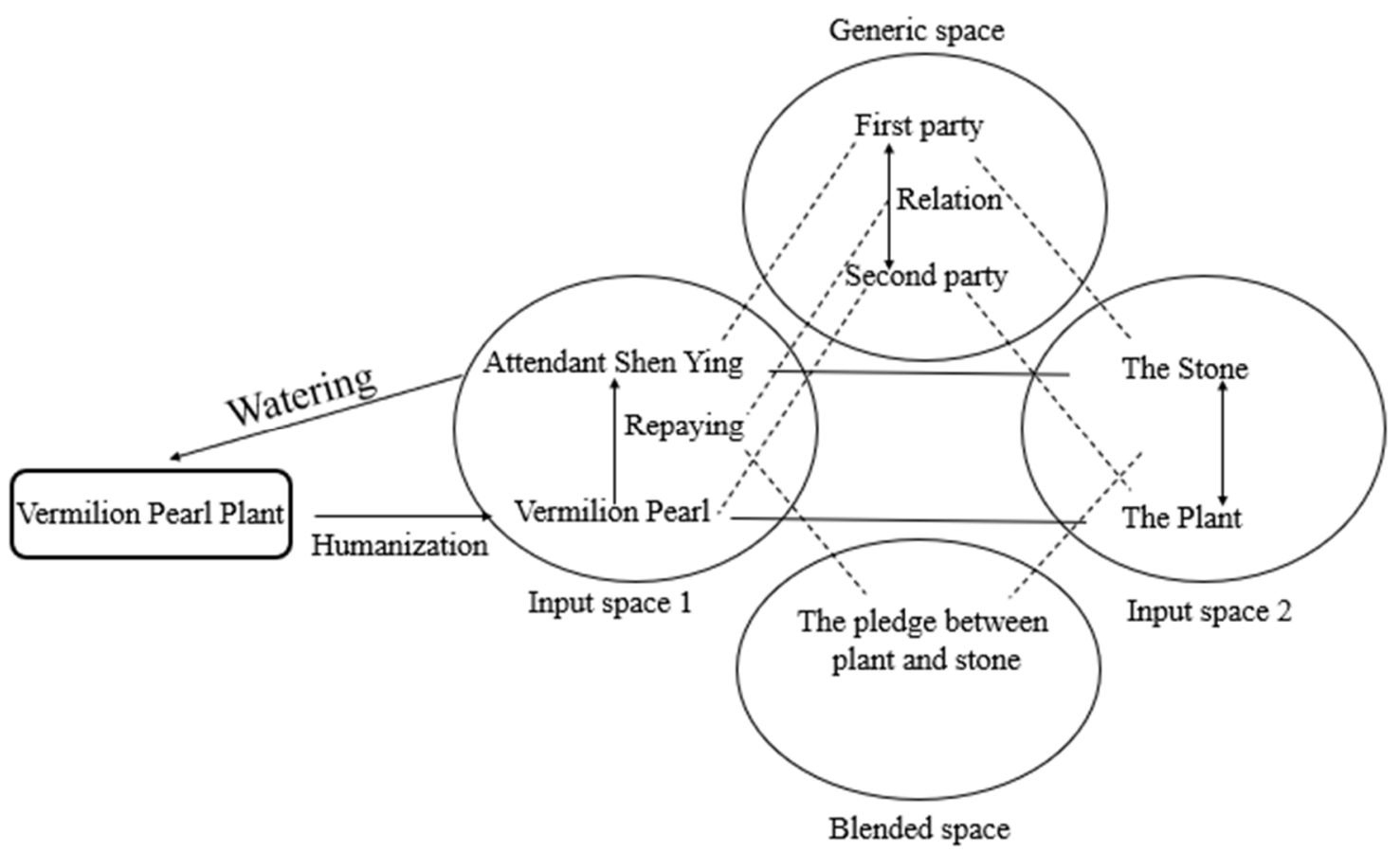

Figure 2. Integration Network 3 


\subsubsection{Integration Network of 'The Pledge Between Plant and Stone' in the Fictional Human World}

In the novel, the leading characters Jia Baoyu and Lin Daiyu mention 'the pledge between plant and stone' in chapter 29 and 36 respectively.

In chapter 29, the Imperial Consent, Baoyu's sister, sends over presents for the Dragon-Boat Festival. However, among all the girls, only Xue Baochai, the leading role in Jin's marriage, receives the same number of presents as Jia Baoyu. This implies that the family intends to let Xue Baochai marry Jia Baoyu which extremely worries Lin Daiyu. Therefore, Jia Baoyu sends his presents to Lin Daiyu and let her take whatever she likes. But she refuses his kindness. And here goes the conversation:

Where Chinese characters have been provided, the official translation from Yang Xianyi will be presented underneath.

宝玉听说, 便命人收了。刚洗了脸出来, 要往贾母那里请安去, 只见林黛玉顶头来了。宝玉赶上去笑道: “我的东西叫你拣，你怎么不拣? ”林黛玉昨日所恼宝玉的心事早又丢开，又顾今日的事了，因说道: “我 没这么大福禁受, 比不得宝姑娘什么金什么玉的, 我们不过是草木之人! ” (《红楼梦》第二十八回)

He had the things put away then and washed his face before setting off to pay his respects to his grandmother. Meeting Daiyu on the way, he hurried up to her with a smile.

'Why didn't you pick any of my things, as I asked?'

Daiyu had forgotten her earlier grievance in her preoccupation with this new incident.

'I'm not cut out for such good fortune,' she said. 'I can't compare with Cousin Baochai and her gold and jade. I'm just as common as any plant or tree.' (Yang: 419)

According to the conversation, Daiyu considers she cannot match with Xue Baochai who comes from a respectable family. She is also jealous about traditional Jin's marriage which is blessed by everyone. Therefore, she confesses to Baoyu that she is merely as ordinary and plain as the plant which does not have the same status with the jade. Here an implication that Daiyu represents the plant can be found according to the author's description.

Likewise, in chapter 36, Xue Baochai sitting next to the bed of Jia Baoyu hears about his words in the dream:

Where Chinese characters have been provided, the official translation from Yang Xianyi will be presented underneath.

这里宝钗只刚做了两三个花瓣, 忽见宝玉在梦中喊骂说: “和尚道士的话如何信得? 什么是金玉姻缘, 我 偏说是木石姻缘! ”(《红楼梦》 第三十六回)

Baochai inside had embroidered two or three petals when Baoyu started calling out in his sleep:

'Who believes what those bonzes and Taoists say? A match between gold and jade? Nonsense! Between wood and stone more likely, I'd say.' (Yang: 524-525)

In the conversation, Jia Baoyu expresses his own thoughts unconsciously that he has a preference for the pledge between plant and stone rather than Jin's marriage. This reveals the link between Jia Baoyu and the stone in the metaphorical expression.

Integrational network 1, the network of 'the pledge between plant and stone' in the fictional human world is built based on the above data.

Figure 3 presents the network of 'the pledge between plant and stone' in the fictional human world and it belongs to a simplex network. The plant and stone in input space 1 belong to the frame of natural objects, whose pledge relation is projected into the blended space. In input space 2, Jia Baoyu and Lin Daiyu who belong to the homo frame are projected into the blended space. And the emergent structure generated in blended space is the spontaneous and natural expression of love between the two leading characters.

The integration network of 'the pledge between plant and stone' in the fictional human world confesses expressively the pure and sincere love between Jia Baoyu and Lin Daiyu. The cognitive tool, metaphor, adds aesthetic perception to this classic work. 


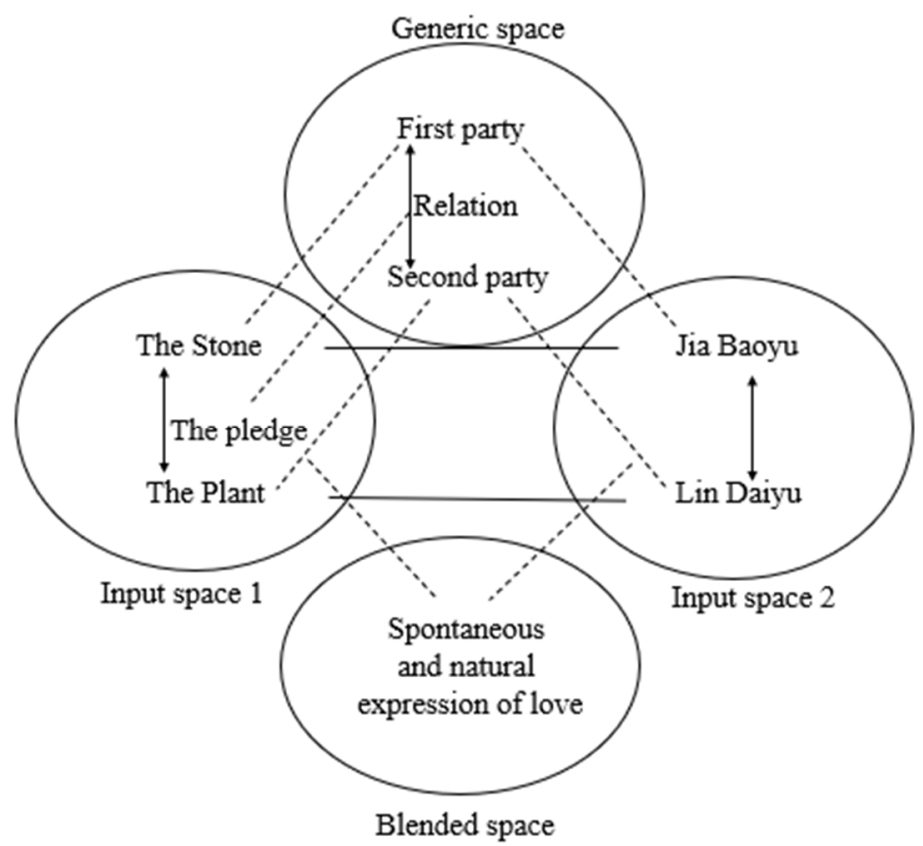

Figure 3. Integration Network 1

\subsubsection{Nested Integration Network}

The links between Attendant Shen Ying and Vermilion Pearl in the mythological narrative space with Jia Baoyu and Lin Daiyu respectively in the real narrative space are quite obvious: all through this novel, the first time Lin appears is in chapter 2 and she dies in chapter 98 . In the nearly 100 chapters, she cries, mainly in the first forty chapters for the love between Jia Baoyu and her for more than 40 times. So, there are enough reasons to argue that Lin Daiyu crying for her love has close links with Vermilion Pearl repaying the gratitude of Attendant Shen Ying. Whereas, no direct description can be found to link these two narrative spaces. An interesting phenomenon that should be pointed out is that through the analysis of the integration networks, both these two narrative spaces have direct relations with the third party, the plant and stone (the space of natural object). In other words, the space of natural object serves as a bridge to combine these two integration networks which are not in the same narrative level.

It is necessary to build a new structure of integration network which nested the previous two networks together to illustrate the metaphoric effects from the mythological characters to the real-world figures. The researchers call it 'nested integration network'.

Figure 4 shows this integration network, nested integration network. According to Figure 4, all three input spaces share the same generic space. Input space 1 and 3 do not have a direct link, and these are integration network 1 and 3 stated before ('the pledge between plant and stone' is under the mythological narrative space). Then blended space 1 maps with blended space 2 which are transformed into input space 4 and 5 respectively to form the 'crossspace integration network' (highlighted in the red square). They are projected and integrated in the blended space 3. 'Love based on the myth of repaying' is generated in blended space 3 which endows the love between the leading characters a mythological meaning and completes the whole cognitive process from mythological narrative space to the real narrative space. 


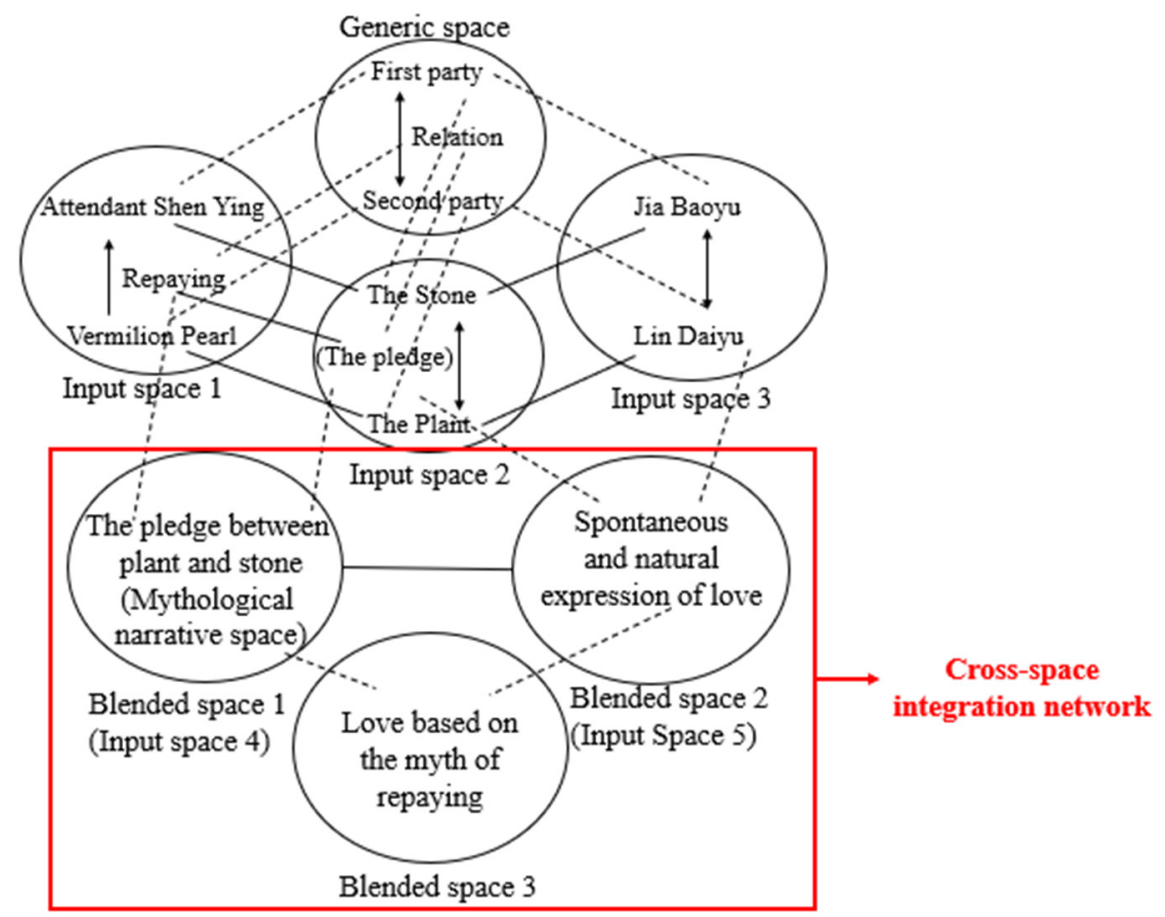

Figure 4. Nested Integration Network

\subsection{Themes of the Novel}

\subsubsection{Integration network of 'Jin's marriage'}

Unlike 'the pledge between plant and stone', Jin's marriage does not possess a mythological origin and an integration network in the fictional human world. It is first depicted through the conversation of Jia Baoyu and Xue Baochai in chapter 8. This chapter narrates the scene where Xue Baochai and Jia Baoyu exchange their treasures and find that their treasures match with each other:

Where Chinese characters have been provided, the official translation from Yang Xianyi will be presented underneath.

宝玉看了, 也念了两遍, 又念自己的两遍, 因笑问: “姐姐, 这八个字倒和我的是一对儿。”莺儿笑道: “是 个癫头和尚送的, 他说必须暂在金器上一一”宝钗不等他说完, 便嗔着:“不去倒茶!”一面又问宝玉从那里 来。（《红楼梦》第八回）

Baoyu read this twice, then twice repeated his own.

'Why, cousin, this inscription of yours matches mine exactly,' he declared laughingly.

'It was given her by a scabby monk,' explained Yinger. 'He said it must be engraved on something made of gold.'

Before she could say more Baochai called her to task for not bringing them some tea. Then she asked Baoyu where he had come from. (Yang: 157-160)

It should be pointed out that Baochai, a well-educated girl being so intelligent is almost unlikely to ignore the fact that her locket matches with Baoyu's jade. Therefore, she might deliberately induce Baoyu to find out the secret of Jin's marriage by himself since she might also have an affection towards Baoyu.

Jin's marriage influences almost all the people ranging from the two leading characters Jia Baoyu and Lin Daiyu to their relatives and even the servants. Since it is a well-known tradition believed and worshiped by all the people, everyone holds the opinion that Jia Baoyu is doomed to marry Xue Baochai. As a result, Lin Daiyu is usually disturbed by this tradition as written below:

Where Chinese characters have been provided, the official translation from Yang Xianyi will be presented underneath.

黛玉点头叹笑道: “蚟才, 蚌才! 你有玉, 人家就有金来配你, 人家有冷香, 你就没有暖香去配? ” (第十 九回） 
Daiyu shook her head with a sigh. 'How dense you are! You have jade, and someone else has gold to match it. So, don't you have a warm scent to match her cold scent?' (Yang: 383)

Jin's marriage is a deeply-held belief by nearly everyone. However, both Jia Baoyu and Lin Daiyu wishes to fight against this belief. It is hard to oppose everyone especially for Daiyu who is an orphan depended on her relatives to live. Only Jia Baoyu and Lady Dowager truly care for Daiyu. Therefore, her affection for Baoyu cannot be obvious. Whereas, she desires to reassure that Jia Baoyu is after her own heart and shares the same opinion with her to stand against Jin's marriage. So, every time she is jealous of the relations between Jia Baoyu and other girls, she would mention Jin's marriage to test the feeling Jia Baoyu has for her and also remind herself that their combination is a tough one. Apparently, Jin's marriage serves as the hardest obstacle for the two loving pairs, Jia Baoyu and Lin Daiyu, to come together.

Apart from Lin Daiyu, there are also descriptions of other people's reaction to Jin's marriage:

Where Chinese characters have been provided, the official translation from Yang Xianyi will be presented underneath.

薛蟠见宝钗说的话句句有理, 难以驳正, 比母亲的话反难回答, 因此便要设法拿话堵回他去, 就无人敢拦 自己的话了, 也因正在气头上, 未曾想话之轻重, 便说道: “好妹妹, 你不用和我闹, 我早知道你的心了。

从先妈和我说, 你这金要拣有玉的才可正配。你留了心, 见宝玉有那劳什子, 你自然如今行动护着他。” (《红楼梦》, 第三十四回, 第 275 页。)

As all her arguments were so reasonable and even harder to refute than his mother's, Xue Pan cast about for some way to silence her in order to have his say. And being in a towering rage, he did not trouble to weigh his words carefully.

'It's no use flying into a huff with me, my dear sister,' he sneered. 'I can see into your heart. Mother's told me about your gold locket which has to be matched with jade. Naturally you looked round carefully, and now that you find Baoyu has that rubbishy thing you're bound to take his side.' (Yang: 684)

Xue Pan, Baochai's brother, is a rough fellow who is not smart. So, he usually says whatever he thinks regardless of the result. However, what he says is just the truth which has been given tacit consent to. It is just because in ancient China, girls of a prominent family are supposed to have a reserved manner that Baochai is unwilling to hear others gossip about Jia Baoyu and her.

In a word, it is obvious that Jin's marriage is a doomed fact for the three leading characters. It is blessed by all the people in Jia's mansions. And it is also the kind of marriage between families of equal social status.

The integration network of Jin's marriage based on the above data is as follows:

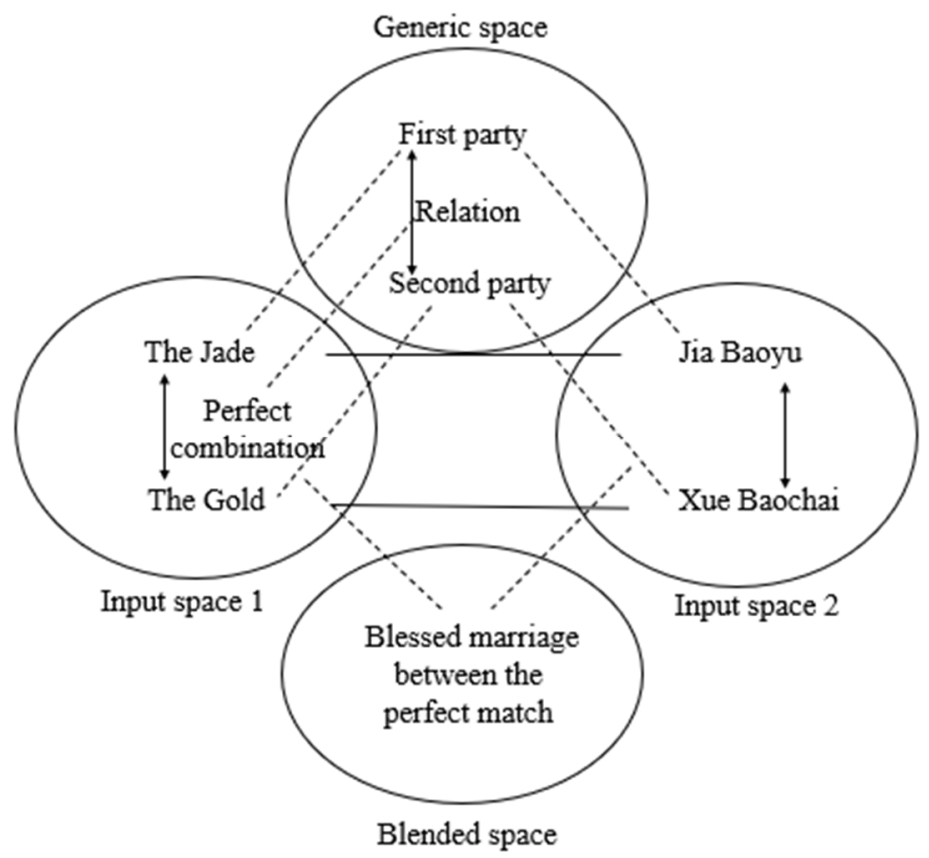

Figure 5. Integration Network 2 
Figure 5 illustrates the details of integration network 2. It is a single-blended network with the frame of the jade and gold being the dominant structure in the blended space. According to the entrenched metaphorical expressions, the jade and gold are the representation of people with high social status or good virtues. Since both Jia Baoyu and Xue Baochai are well-educated people born in a decent family, they are considered as the perfect combination, specifically the so-called 'golden boy and jade girl' in Chinese. Additionally, Jia Baoyu is born with a rare jade which is considered as his life-line. Accordingly, Xue Baochai also carries a golden lock given by the monk. Therefore, there exist relations between the gold and jade and Jia Baoyu and Xue Baochai. The gold and jade in input space 1 belong to the object frame while Jia Baoyu and Xue Baochai in input space 2 are in the homo frame. The perfect combination in input space 1 is projected into the blended space together with the two characters in input space 2. After the integration, there comes the emergent structure, namely, blessed marriage between the perfect match.

This is the whole cognitive process of 'Jin's marriage'. Just like the integration network of 'the pledge between plant and stone' in the fictional human world, this network paves the way for the understanding of the relation between Jia Baoyu and Xue Baochai. The concept of a perfect match is fully embedded in their marriage.

\subsubsection{Comparison Between the two Love Allusions}

To answer the second question about the theme of this novel, the researchers now compare the two love allusions concerning the three leading characters by applying CIT. The following analysis is based on the integration networks built in section 4.1.2 and section 4.2.1.

When comparing Figure 3 with Figure 5, several features can be concluded:1) the huge difference between the personalities of Lin Daiyu and Xue Baochai; 2) the dual identities of Jia Baoyu in the two integration networks; 3) the opposite emergent structures in the two blended spaces

Table 1 combines Figure 3 and Figure 5 to make further comparison:

Table 1. Comparison of the two love allusions

\begin{tabular}{|c|c|c|c|c|c|}
\hline & \multicolumn{2}{|c|}{ Input Space 1} & \multicolumn{2}{|c|}{ Input Space 2} & \multirow{2}{*}{ Blended Space } \\
\hline & Object & Features & Figure & Personalities & \\
\hline \multirow{2}{*}{$\begin{array}{l}\text { The pledge } \\
\text { between } \\
\text { plant and } \\
\text { stone }\end{array}$} & The plant & $\begin{array}{l}\text { Ordinary; Repaying } \\
\text { with tear }\end{array}$ & Lin Daiyu & $\begin{array}{l}\text { Depending on others; } \\
\text { Sensitive }\end{array}$ & \multirow{2}{*}{$\begin{array}{l}\text { Natural and } \\
\text { spontaneous } \\
\text { love }\end{array}$} \\
\hline & The stone & $\begin{array}{l}\text { Natural belonging; } \\
\text { Authentic }\end{array}$ & Jia Baoyu & $\begin{array}{l}\text { Counterculture; } \\
\text { Refuse to associate } \\
\text { with the world }\end{array}$ & \\
\hline \multirow{2}{*}{$\begin{array}{l}\text { Jin's } \\
\text { marriage }\end{array}$} & The gold & Valuable treasure & Xue Baochai & $\begin{array}{l}\text { Well-behaved; Born } \\
\text { in a decent family }\end{array}$ & \multirow{2}{*}{$\begin{array}{l}\text { Blessed and } \\
\text { perfect } \\
\text { marriage }\end{array}$} \\
\hline & The jade & Valuable treasure & Jia Baoyu & $\begin{array}{l}\text { Born with the jade in } \\
\text { a prominent family }\end{array}$ & \\
\hline
\end{tabular}

\section{(a) Comparison between Lin Daiyu and Xue Baochai}

They are the two leading ladies in the novel. Both of them are of great talent in poetry and have lovely complexity. However, Lin Daiyu is extremely sensitive and somewhat narrow-minded. Since both of her parents died, she has to depend on her relatives to live. Therefore, she usually feels lonely and isolated. Jia Baoyu is the person who stays with her ever since their childhood. She views him as her soul mate and emotional sustenance. And she is the only person who never persuades Jia Baoyu to take the road of official career. So, her love for him is as pure and sincere as what the mythological story tells. By comparison, Xue Baochai is a girl from a respectable family and capable of dealing with all men. She is a considerate person loved by all the people in Jia's mansion even by Lin Daiyu. She is a perfect wife in the traditional sense. She usually persuades Jia Baoyu to take the imperial examination and to be the dignitary. Her feeling towards Jia Baoyu is originated more from the conventional belief that a decent girl should marry a husband with high social status. Therefore, she sticks to the social tradition at that times.

\section{(b) Comparison of Jia Baoyu's dual identities}

As the leading character, Jia Baoyu is a significant personage in Jia's mansion and a person with dual identities. On the surface, he is of high social status adoring by all the people around him and also shouldering the obligation of supporting his family. The jade held in his mouth at his birth implies his identity of 'jade'. Whereas, his true 
disposition is opposite to the traditional belief. Surrounded by girls, Jia Baoyu is a sensitive and emotional person who detests and rejects the bureaucracy. He hates the traditional concepts for career and marriage which view frame, wealth and social status as the top priority. What he chases after is the true, the good and the beautiful. In this sense, it is the stone which represents Jia Baoyu's true disposition (the identity of 'stone').

(c) Comparison of the blended spaces

By compressing the relationships of the leading characters with that of the corresponding objects, the true essence of the relations can be expressed. The pledge between plant and stone is the expression of true emotion. It is free from the vulgar pursuit of fame and wealth but the match of the heart and soul. However, this pledge under the background of the feudal society is hard to achieve. By comparison, Jin's marriage is the perfect match blessed by all the people. This kind of well-matched marriage is highly praised and the so-called 'right path'. At that time, men who long to come to the fore have to take the imperial examination to get on the official career and women to marry the right person who is of high social status. Under this social culture, the freedom to chase true love and choose the right spouse is almost unrealistic. Therefore, the author creates such a rebellious figure, Jia Baoyu to give an expression of his discontent with the marriage for the purpose of material gains and his frustration towards the social standard to judge the value of people which stifles lots of talents. Additionally, by giving affirmation to the love between Jia Baoyu and Lin Daiyu, Cao Xueqing also advocates the idea of freedom to love and to show the true disposition of oneself.

\subsection{Summary}

By building the networks of 'the pledge between plant and stone', certain relations between the mythological figure, the love tokens and the main characters can be concluded. Both the mythological figures and the main characters are directly related to the plant and stone. Whereas, through the analysis of data, it has been found out that a certain link also exists between mythological figures and the main characters. Therefore, a new the structure of integration network is built with three input spaces to reveal the hidden relationships of these two comparing pairs. And it is called 'nested integration network'. Therefore, the purpose for the writer to create the myth at the very beginning of the novel is to endow a new explanation to the plant and stone so that they can match with the personalities of the leading characters, Jia Baoyu and Lin Daiyu.

On the other hand, the analysis of Jin's marriage also focuses on building integration networks. In the end, by comparing the integration networks of the two love allusions, part of the themes of this novel can be arrived at. The author Cao Xueqing creates the rebellious character Jia Baoyu to express his frustration and disapproval towards the marriage aimed at fame and wealth and the dissatisfaction of the only career path which covers up many talents.

\section{Conclusion}

This paper investigates two love allusions in A Dream of Red Mansions under the Conceptual Integration Theory.

The countercultural essence of the plant and stone is embodied in the integration networks between the love tokens and the mythological figures. The myth created at the beginning of the novel endows an anti-entrenched explanation to the plant and stone. This enables the metaphorical process between the plant and stone and Jia Baoyu and Lin Daiyu later in the novels.

When constructing the integration network between the mythological characters and Jia Baoyu and Lin Daiyu, a new structure 'nested integration network' is adopted with three input spaces. This new structure has the transmission function which enables readers to build integration networks between the comparing units in separated layers.

By correlating the integration networks of the two love allusions, it is clear that the author Cao Xueqing creates two opposite networks. Though in the end, it seems that the perfect match of Jin's marriage surpasses the natural pledge between plant and stone, it is the pledge which, at a deeper level, is more profoundly rooted in both the author and readers' hearts. Cao Xueqing shows his powerless rebellion against corrupted feudal thought by the love tragedy of the leading characters.

From the perspective of literary analysis, the researchers come up with new ideas to illustrate the love allusions throughout the text. From the perspective of cognitive linguistics, the researchers enlarge its database and, more importantly, propose a new structure of integration network.

\section{Acknowledgments}

The research is supported by a grant from Guangdong Province, China, for the key Project of Pragmatic Culture and Identity Construction (Grant Number 2018WCXTD002). 


\section{References}

Atran, S. (2002). A metamodule for conceptual integration: Language or theory of mind? Behavioral and Brain Sciences, 25(6), 674-675. http://doi.org/10.1017/S0140525X02220129

Cao, Xueqin, \& Gao, E. (1994). A Dream of Red Mansions. Trans. Yang Xianyi., and Gladys Yang. Beijing: Foreign Languages Press.

Cao, Xueqin, \& Gao, E. (2016). A Dream of Red Mansions. Beijing: Commercial Press.

Charteris-Black. (2004). Corpus Approaches to Critical Metaphor Analysis, Basingstoke: Palgrave Macmillan.

Chen, Hong. (2016). Hong Loumeng 'mushi' kaolun (Research on 'plant and stone' in A Dream of Red Mansions). Wenxue yu Wenhua (Journal of Literature and Culture), (3): 24-35. http://doi.org/ 10.13896/j.cnki.wxywh.2016.03.004

Cheng, Yige, Peng, Chen, \& Huang, Qun (2017). Gainianzhenghe shijiao xia Hong Loumeng zhong mingzi de yuyin yinyu (Phonetic metaphor in A Dream of Red Mansions through conceptual integration). Haiwai Yingyu (Journal of Overseas English), (3): 197-198

Coulson, S., \& Oakley, T. (2005). Blending and coded meaning: Literal and figurative meaning in cognitive semantics. Journal of Pragmatics, 37(10), 1510-1536. https://doi.org/10.1016/j.pragma.2004.09.010

Fauconnier, G. (1997). Mappings in Thought and Language. London: Cambridge University Press. https://doi.org/10.1017/CBO9781139174220

Grady, J. (2005). Primary metaphors as inputs to conceptual integration. Journal of Pragmatics 37.10:0-1614. https://doi.org/10.1016/j.pragma.2004.03.012

Grady, J., \& Mark Turner. (2002). The Way We Think. New York: Basic Books.

Huang, Chonghao. (2001). Liangxing chongbai yu mushi qianmeng (Worship of both sexes and 'the pledge between plant and stone'). Huang Gang Shifan Xueyuan Xuebao (Journal of Huang Gang Normal University), (6), 20-23

Lakoff, G., \& Mark J. (2003) Metaphors we live by. London: The university of Chicago Press. https://doi.org/10.7208/chicago/9780226470993.001.0001

Lan, chun. (2013). Cong Renzhi Shijiao Kan Fojing Baojijing Zhong de Biyu (A Cognitive Perspective on the metaphors in the Treasure Machine Sutra). Zhongguo Waiyu (Foreign Language China), 9(4), 25-33. http://doi.org/10.13564/j.cnki.issn.1672-9382.2012.04.019

Li, Ye. (2006). Hong Loumeng 'mushi qianmeng' yuanxing de wenhua kaozheng (Cultural research on 'the pledge between plant and stone' in A Dream of Red Mansions). Liao Cheng Daxue Xuebao: Shehui Kexue Ban (Journal of Liao Cheng University: Social Science Edition), (6), 80-81. https://doi.org/10.16284/j.cnki.cn371401/c.2006.06.020

Meiners, S., Pickett, S., \& Cadenasso, M. (2015). Conceptual frameworks and integration: Drivers and theory. In An Integrative Approach to Successional Dynamics: Tempo and Mode of Vegetation Change (pp. 48-64). Cambridge: Cambridge University Press. https://doi.org/10.1017/CBO9780511844218.005

Oakley, T., \& Pascual, E. (2017). Conceptual Blending Theory. In B. Dancygier (Ed.), The Cambridge Handbook of Cognitive Linguistics (Cambridge Handbooks in Language and Linguistics, pp. 423-448). Cambridge: Cambridge University Press. https://doi.org/10.1017/9781316339732.027

Sun, Yi. (2019). Dangdai Yinyuxue de Lilun Fanshi Gounian (The theoretical paradigm of contempory metaphor research). Hainan Daxue Xuebao Renwen Shehui Kexue Ban (Journal of Hainan University Humanities and Social Sciences), 37(6), 126-134.

Tang, Yingling. (2018). On the Semantic Mapping Mechanism between the Jingling Registers in A Dream of Red Mansions and Related Characters from the Perspective of Conceptual Blending Theory. Diss. Sichuan Normal University.

Xu, Jie. (2012). A Study On Metaphor Translation In Hong Lou Meng From the Perspective of Conceptual Blending Theory Diss. Shanghai International Studies University.

Xu, Zhongrong. (2018). Hong Loumeng zhong 'mushi' yixiang de wenben yiyi bulun (Supplementary discussion about the textual meaning of 'plant and stone' in A Dream of Red Mansions). Tian Zhong Xuekan (Journal of Tian Zhong), 33(2), 107-112. http://doi.org/ 10.14058/j.cnki.tzxk.2018.02.019 
Yang, Jiayou, \& Yang, Jianhong (2010). 'Jinyu liangyuan' yu 'mushi qianmeng' de sixiang jiedu (Research on 'Jin's marriage' and 'the pledge between plant and stone'). Lan Zhou Xuekan (Journal of Lanzhou), (8), 160162. https://doi.org/10.4028/www.scientific.net/AMR.160-162.1257

Yu, Shulin. (2010). Application of Conversational Implicature Theory to The Analysis of The Utterances in A Dream of Red Mansions - Case Studies of The Maids'Utterances Diss. University of Electronic Science and Technology of China.

Zheng, Chenyin (2000). Cong mushi chongbai kan Hong Loumeng zhi 'mushi qiyuan' ('The pledge between plant and stone' in A Dream of Red Mansions judging from worship of plant and stone). Hong Loumeng Xuekan (Journal of A Dream of Red Mansions), 03, 104-113.

Zhou, Ruchang. (2013). Honglou duomu hong (Red buildings dazzling red). Bei Jing: Writer Press.

\section{Copyrights}

Copyright for this article is retained by the author(s), with first publication rights granted to the journal.

This is an open-access article distributed under the terms and conditions of the Creative Commons Attribution license (http://creativecommons.org/licenses/by/4.0/). 